\title{
$\angle$ Research Square \\ The Stigma of Digital Amputation: A Survey of Amputees with Analysis of Risk Factors
}

\section{Carrie Roth Bettlach}

Washington University School of Medicine in Saint Louis: Washington University in St Louis School of Medicine

\section{Ella Gibson}

Washington University School of Medicine in Saint Louis: Washington University in St Louis School of Medicine

\section{John M Daines}

Washington University School of Medicine in Saint Louis: Washington University in St Louis School of Medicine

\section{Emma R payne}

Washington University School of Medicine in Saint Louis: Washington University in St Louis School of Medicine

\section{Linh N Vuong}

Washington University School of Medicine in Saint Louis: Washington University in St Louis School of Medicine

\section{Corinne M Merrill}

Washington University School of Medicine in Saint Louis: Washington University in St Louis School of Medicine

\section{Mitchell Andrew Pet ( $\nabla$ mitchell.pet@gmail.com )}

Washington University School of Medicine in Saint Louis: Washington University in St Louis School of Medicine https://orcid.org/0000-0002-5072-1733

\section{Research Article}

Keywords: Stigma, Digital Amputation, Hand Surgery, Trauma

Posted Date: March 16th, 2021

DOl: https://doi.org/10.21203/rs.3.rs-249646/v1

License: (1) This work is licensed under a Creative Commons Attribution 4.0 International License. Read Full License 
Version of Record: A version of this preprint was published at Journal of Hand Surgery (European Volume) on September 9th, 2021. See the published version at https://doi.org/10.1177/17531934211044642. 


\section{Abstract}

Purpose: We aimed to quantify the stigma associated with digital amputation using the Neuro-QOL Stigma patient-reported outcomes instrument and examine the patient and injury factors associated with a more severe amputation stigma experience.

Methods: This descriptive retrospective cohort study analyzed 164 patients who underwent digital amputation. Records were reviewed for age at amputation, sex, indication, laterality, level, number of amputated digits, and a diagnosis of depression that preceded amputation. Enrolled patients remotely completed the Neuro-QOL stigma computer adaptive test, a battery of PROMIS instruments, and a questionnaire clarifying personal/injury details. Multivariable analysis was used to identity factors associated with a more severe stigma experience.

Results: Among 164 digital amputees enrolled, the observed mean Neuro-QOL Stigma score of $47.2+/-8$ is slightly below the population mean of 50 . Younger age, a worker's compensation claim, and a diagnosis of depression at the time of amputation are each independently associated with a more severe stigma experience after digital amputation. Neither socioeconomic variables, anatomic details of the injury, nor mechanism were independently associated with Neuro-QOL Stigma.

Conclusions: While we have previously targeted patients with more severe injuries for discussion of coping with physical stigma, our findings suggest that attention should perhaps instead be focused on digital amputees who are young, depressed, and/or involved with worker's compensation. A surgeon may be of service to the at-risk patient by offering referral to a mental health provider who can offer depression treatment and/or support the patient's process of coping and adjustment.

\section{Introduction}

Stigma is defined as "the situation of the individual who is disqualified from full social acceptance" $[1,2]$ and it involves both enacted and internalized components.[3] Enacted stigma refers to negative attitudes expressed by a community towards a person with a devalued characteristic, and may result in negative consequences like fear, avoidance, and/or discrimination. This enacted experience may result in internalized stigma, which is when this person comes to personally endorse the negative public attitudes such that they self-stigmatize.[3] This is associated with a variety of negative outcomes such as selfisolation, low self-esteem, poor self-efficacy, low quality of life, and failure to pursue employment and independence.[3]

Stigma may result from a variety of potentially devalued conditions including but not limited to behaviors, race/ethnicity, social status, and mental or physical disabilities.[4] Limb conditions including scarring, congenital differences, and amputations are known to carry stigma,[4-6] and there is evidence supporting the possibility of stigma associated with digital amputation.[7-9] In fact, the expectation of stigma for digital amputees has been cited as justification for noncritical replantation[7-11] and advanced prosthetic digit fabrication.[12-14] 
Surveys of patients with stigmatizing conditions are an important part of understanding their stigma experience.[15-17] However, previous studies of digital amputation stigma have been limited to surveys of surgeons and the general non-amputee public regarding expectations and assumptions surrounding a theoretical amputee's experience. Given the potential implications for indicating replantation/digit preservation, or simply for counseling new amputees in an evidence-based manner, this absence of patient-reported data from digital amputees represents a meaningful deficit in the literature.

The primary objective of this study is to quantify the stigma associated with digital amputation using information gathered directly from digital amputees using the Neurology Quality of Life (Neuro-QOL) Stigma patient-reported outcomes (PRO) instrument. This is a computer adaptive test (CAT) which has been designed to measure the combination of both enacted an internalized stigma.[3] Although it was designed and validated in patients with neurological diseases,[3] it has been broadly applied including among patients with upper extremity conditions.[7-9] Furthermore, recognizing that digital amputees are a heterogeneous population, we aimed to examine the patient and injury factors (present at the time of amputation) associated with an individual's stigma experience. We also sought to evaluate how stigma correlates with other psychosocial and functional outcomes. Our primary hypothesis was that digital amputees would report stigma in excess of the population mean, and that age, mental health conditions, and injury severity would meaningfully impact the degree of stigma experienced.

\section{Materials And Methods}

This is a descriptive retrospective cohort study of digital amputees. After receiving approval from the Washington University School of Medicine institutional review board, CPT and ICD-9/10 databases were queried for all patients undergoing digital amputation or revision amputation between April 2010 and April 2020. Medical records were reviewed for age at amputation, sex, indication for amputation, laterality, level, and number of amputated digits. Depression that preceded the amputation (as evidenced by a formal diagnosis or documentation of a prescription for that indication) were recorded from the chart. The patient's home address was used to determine their area deprivation index (ADI), $[18,19]$ a measure of socioeconomic disadvantage and deprivation that has been used in several upper extremity outcomes studies (higher score represent greater deprivation).[20-23]

Inclusion criteria for study enrollment were one or more digital amputations sustained within the study period and age $\geq 18$ years at the time of injury. Eligible patients were contacted by telephone. After a scripted explanation of the study it was requested that each patient complete a battery of electronically administered PRO questionnaires. Patients who were deceased, unable to be contacted, unwilling/unable to receive the PRO questionnaires, unable to provide informed consent, and those unable to comfortably communicate in English were excluded. Consenting patients provided an email or cellular phone number where they could receive a personalized and secure link to the study PROs instruments, which were administered remotely. The CAT questionnaires administered in this study were: Neuro-QOL Stigma v1.0 (CAT item bank available in Appendix 1), Patient Reported Outcome Measurement System (PROMIS) Anger v1.1, PROMIS Anxiety v1.0, PROMIS Depression v1.0, PROMIS Upper Extremity Function v2.0 (UE), 
PROMIS Ability to Participate in Social Roles and Activities v2.0, and PROMIS Pain Interference v1.1, in addition to a short questionnaire clarifying handedness, ethnicity, education level, and worker's compensation (WC) status. All PRO instruments in this study have a reference population mean of 50 and standard deviation of 10 , with higher scores indicating more of the concept being measured. For example, a Neuro-QOL Stigma score of 60 represents a high-stigma experience, which is one standard deviation in excess of the reference population mean.

\section{Statistical methods}

Explanatory variables were treated as dichotomous, interval, or continuous. Education was dichotomized ( $0=$ less educated, $1=$ more educated) based upon whether or not the patient had completed an Associate's degree or higher. The most proximal amputation level was dichotomized ( $0=$ distal, $1=$ proximal) based upon preservation (or loss) of the proximal interphalangeal joint in non-thumb digits and/or preservation (or loss) the proximal phalangeal head in thumbs. Comparison of means was accomplished using a twotailed student's t-test. Intergroup comparison of proportions was accomplished using a chi-squared test. Bivariate relationships between all explanatory variables and the primary outcome variable (Neuro-QOL Stigma) were assessed using linear regression. Explanatory variables with bivariate $p$ values $\leq 0.2$ were entered into the multivariable regression. Multivariable analysis was achieved using stepwise regression. Correlation between primary and secondary outcome variables was assessed using Pearson's $r$. Statistical significance was defined as $p<0.05$.

Conservative a priori power calculation revealed that in order to obtain $80 \%$ power for detection of a moderate effect size $\left(f^{2}=0.15\right)[24,25]$ in a multivariable model with up to 10 entrant explanatory variables, a minimum sample of 118 subjects would be required.

\section{Results}

Database query yielded 1109 patients with qualifying amputations. Exclusion for deceased status, unable to contact, unwilling/unable to consent, and failure to return questionnaires is detailed in Figure 1. 164 patients ultimately completed follow-up questionnaires. Demographic and injury details for the entire digital amputee cohort and the follow-up study cohort are compared in Tables 1 and 2. Compared to all qualifying digital amputees, the surveyed group is older, more likely to be white, less deprived, and more recently amputated. Furthermore, females and non-WC cases were over-represented in the followup group. 15/164 (9\%) patients had a diagnosis of depression at the time of amputation. Mean NeuroQOL stigma score in the follow-up cohort was $47.2+/-8$. A histogram of Neuro-QOL Stigma scores for the sample is shown in in Figure 2.

\section{Patient and Injury Factors Associated with Stigma Experience}

Bivariate analysis (Table 3 ) revealed that among all explanatory variables, younger age at amputation, higher ADI, less education, WC status, and a diagnosis of depression at the time of amputation are 
associated with a significantly worse stigma experience after digital amputation. Neither sex, number of amputated digits, thumb involvement, amputation level, dominance of the injured side, nor a traumatic mechanism were associated with Neuro-QOL Stigma. Because the responding population was overwhelmingly (89\%) White, the impact of ethnicity could not appropriately be analyzed.

Seven explanatory variables (age at amputation, ADI, education, depression, number of amputated digits, dominance of the injured side, WC status) had bivariate $p$-values $<0.20$ and thus met criteria for entrance in to the multivariable model. Multivariable analysis (Table 4) revealed that among the seven explanatory variables entered into the stepwise regression, only three have independent associations with stigma experience, while the remaining variables do not have significant associations in the model. Specifically, younger age, a WC claim, and a diagnosis of depression at the time of amputation are each independently associated with a more severe stigma experience after digital amputation. The $\mathrm{R}^{2}$ for this model is 0.15 .

\section{Relationship between Neuro-QOL Stigma and Secondary Outcome Measures}

The primary outcome variable (Neuro-QOL Stigma) was found to have statistically significant relationships with other measures of patient outcome (Table 5). Unfavorable scores on PROMIS UE, PROMIS Depression, PROMIS Anxiety, PROMIS Anger, PROMIS Ability to Participate in Social Roles, and PROMIS Pain Interference, were all correlated with higher/worse degrees of stigma.

\section{Discussion}

This study reports the patient-reported stigma experience of digital amputees measured using the NeuroQOL instrument. While the mean Neuro-QOL stigma score was slightly below the population mean, substantial variability was observed and a more severe stigma experience was found to be associated with older patient age, pre-existing depression, and a worker's compensation claim. Notably, neither socioeconomic variables nor injury characteristics were independently associated with stigma.

In a 2016 survey of both surgeons and the general public, Maroukis et al. [7] confirmed that non-surgeon American respondents had a strong preference for attempted replantation. Hand surgeons generally did not share this preference, and the reasons for this discrepancy were investigated. While both parties had similar expectations for the outcome of a successful replantation, there were striking differences in surgeon and non-surgeon expectations surrounding the patient experience after digital amputation. In addition to expecting greater functional impairment, the American public estimated that digital amputees experience substantial stigmatization. Specifically, $40.8 \%$ of the public agreed that digital amputees would be treated unkindly, and $18.4 \%$ agreed that they would be avoided by others, while less than $10 \%$ of surgeons agreed with either of these assertions.

This anticipation by the American general public that digital amputation is a stigmatizing injury has been substantiated by other authors,[8] and the avoidance of this stigma has been used to justify both noncritical replantation[26] and advanced digital prosthetics.[12,14] Despite this, the only evidence 
supporting the existence of digital amputation stigma comes from the suppositions of lay public and surgeons who have never had a digital amputation. The absence of information surrounding the stigma experience of actual digital amputees is a substantial gap in the literature.

In this population of 164 digital amputees, the observed mean Neuro-QOL stigma score of $47.2+/-8$ is slightly below (indicating less stigma than) the population mean of 50 . While the absence of pre-injury PRO data makes it impossible to definitively measure the impact of amputation upon stigma, this result can be reasonably interpreted as evidence that digital amputation is not highly stigmatizing to the average patient in our sample. However, as evidenced by the histogram in Figure 2, there was considerable variability in Neuro-QOL Stigma with scores ranging as high as two standard deviations above the observed mean. This inter-patient variability of stigma severity motivated our analysis of patient and injury factors that might predict an individual amputee's experience. Specifically, we focused on factors present and known at the time of injury such that this information could be used to identify atrisk patients who might benefit from anticipatory supportive measures.

Among the demographic, social, psychiatric, and injury variables examined, only younger age, social deprivation, low education, pre-existing depression, and a WC claim were found to have significant bivariate association with higher stigma. Multivariable regression clarified that among these, only younger age, a WC claim, and depression prior to the amputation were found to have significant independent association with Neuro-QOL Stigma. Using the unstandardized beta coefficients in Table 4, it can be approximated that an age decrease of 16 years is associated with a 2 unit increase in NeuroQOL stigma, while worker's compensation involvement and prior depression are each associated with separate 4-point increases in Neuro-QOL stigma. Though the minimal clinically important difference for the Neuro-QOL stigma scale is not known, the combination of the factors above would be expected to influence a Neuro-QOL stigma score by an amount that approximates one standard deviation.

The finding that younger age is associated an increased perception of stigma is consistent with existing literature on the topic. In a study of 1,216 participants in the National Survey for Midlife Development in the United States, a significant interaction between greater stigma and younger age was observed.[27] The authors explained that with age, individuals are more strongly motivated to regulate their emotional well-being.[28] Thus, older adult may deemphasize stigma-based experiences and show greater emotional resilience relative to younger individuals.[27]

While we are unaware of previous studies examining the impact of depression on the stigma associated with amputation or other readily apparent physical differences, there is precedent for a relationship between these two factors in the chronic pain literature. Naushad et al observed that patients with chronic pain and depression reported greater chronic-pain related stigma than patients with depression alone, and concluded that "the presence of depression appears to be associated with greater experience of nondepression related stigma". [29] This observation is in agreement with the findings of the current study, wherein pre-existing comorbid depression was independently associated with increased patient-reported stigma. While the reason for this association is incompletely understood, analysis of stigma subscale 
data in the study by Naushad et al found that depression was associated a greater need to hide their condition, and made patients more likely to perceive experiences as stigmatizing.[29] While the CAT data in our study are not suited to this type of sub-analysis, it is plausible that these effects might extend to the digital amputee population and cause depressed persons to conceal their amputation and/or perceive daily experiences as stigmatizing.

Given that WC cases have been associated with poor patient reported-outcomes in a wide variety of upper extremity conditions,[30,31] it is not surprising that this factor is also independently associated with increased stigma after digital amputation. It has previously been argued that when an outside agency is playing such a large role in the administration of care, that patients are encouraged to remain in the sick role,[32] which could certainly include a perception (and/or over-reporting) of stigma.

Contrary to our hypothesis that functionally and aesthetically more severe injuries would be associated with increased stigma, we detected no impact of the number of amputated digits, level of amputation, involvement of the thumb, mechanism, or dominance of the injured side. Because concealability, disruptiveness, and aesthetic qualities are among the factors known to exacerbate stigma,[2] this finding was unexpected. We interpret this finding to mean that in digital amputees, patient factors rather than the anatomy/injury factors are the primary drivers of the stigma experience.

While this study was focused on the stigma experience of digital amputees, it is important to recognize that stigma as an outcome does not occur in isolation. In this sample, stigma was significantly correlated with other negative PROs including PROMIS measures of pain interference, depression, anxiety, anger, ability to participate in social roles and activities, and upper extremity function. While a detailed analysis of factors contributing to these specific PRO measures is beyond the scope of this paper, these moderate correlations $(\square \mathrm{r} 0.54-0.69=\mathbb{})$ imply that in many cases, negative outcomes co-occur and likely share similar risk factors. This is consistent with existing evidence that stigma is associated with other negative outcomes,[3] and underscores the clinical relevance of this study.

The most substantial limitation of this study is incomplete follow-up and resultant response bias which was primarily due to inability to contact $54 \%$ of eligible patients, with refusal to participate ( $11 \%)$, and failure to complete a questionnaire after agreeing to do so $(11 \%)$ as secondary contributors. The modest rate of patient enrollment $(164 / 1109,15 \%)$ is likely related to the 10 -year range of eligibility for inclusion, which increases the likelihood that patients' contact information will be out of date. Compared to the entire eligible population, study participants were more likely to be female, white, older, less socioeconomically deprived, recently amputated, and involved in a WC case. This is generally in line with the findings of previous studies which indicate that younger age, male sex, and low income are predictive of survey non-response.[33, 34] The fact that $89 \%$ of respondents were white indicates that that conclusions should not be confidently generalized beyond this group. Furthermore, this single center study has not examined how amputation may affect the stigma experience in different cultures and/or regions. Given the reported negative associations with digital amputation in Eastern cultures,[7-9, 26] it would be illuminating to gather similar data in Asian and Asian-American populations. 
Because this study lacks a non-amputated control group, we are somewhat limited in our ability to assess how the stigma experience of amputees differs from that of non-amputees. Fortunately, this limitation is mitigated by the design of the Neuro-QOL stigma scale which is centered around a reference population mean of 50 . Detection of depression preceding amputation by way of chart review is a method that has been used in similar studies[35], but it is possible that cases could have been missed. Additionally, because the overwhelming majority of patients in this study (90\%) had amputated only 1 or 2 fingers, it is possible that we failed to detect a real impact of more severe injury patterns affecting greater than two fingers. Finally, it should be noted that the Neuro-QOL stigma scale was designed for neurological conditions and has not been specifically validated to measure stigma associated with physical differences. Despite this, the questionnaire contains no condition-specific language, and elements of this questionnaire have been used in prior studies focused on digital amputation.[7-9]

In evaluating a patient's risk for a severe stigma experience after digital amputation, our data suggest that who the patient is may be more important than exactly what happened to their hand. While we have previously targeted patients with more severe injuries for discussion of coping with physical stigma, our findings suggest that attention should perhaps instead be focused on digital amputees who are young, depressed, and/or involved in a WC case. Though the effectiveness of anticipatory psychological support cannot be presumed, a surgeon may be of service to the at-risk patient by offering and encouraging referral to a mental health provider who can offer both depression treatment and/or support the patient's process of coping and adjustment. Future studies should seek to clarify the stigma experience of digital amputees in different cultures, investigate what specific measures can be used to mitigate negative outcomes in at-risk patients, and investigate how digital replantation affects the stigma experience.

\section{Declarations}

Acknowledgements: The authors would like to acknowledge Dr. Ryan Calfee and Dr. Aviram Giladi for their invaluable advice in developing and presenting this study

Funding: Dr. Pet has received research funding from Checkpoint Inc. for unrelated work. Other authors have nothing to disclose. No funding was received for this article from any source.

Conflicts of Interest: Authors have no real or potential conflicts of interest

Availability of Data: Data supporting the findings of this study are submitted with this manuscript in a de-identified manner.

Code Availability: NA

Ethics approval: The Institutional Review Board at Washington University School of Medicine has approved this study. (Approval Number 202005045)

Consent to Participate: All study enrollees provide consent to participate. 
Consent for Publication: Does not contain any identifiable information. NA.

\section{References}

1. Goffman, I., \& Goffman, E. (1963). Stigma; Notes on the Management of Spoiled Identity. Englewood Cliffs, N.J. : Prentice-Hall.

2. Rao, D., Choi, S. W., Victorson, D., Bode, R., Peterman, A., Heinemann, A., \& Cella, D. (2009). Measuring stigma across neurological conditions: the development of the stigma scale for chronic illness (SSCI). Quality of Life Research, 18(5), 585-595. doi:10.1007/s11136-009-9475-1

3. Molina, Y., Choi, S. W., Cella, D., \& Rao, D. (2012). The Stigma Scale for Chronic Illnesses 8-Item Version (SSCl-8): Development, Validation and Use Across Neurological Conditions. International Journal of Behavioral Medicine, 20(3), 450-460. doi:10.1007/s12529-012-9243-4

4. Pachankis, J. E., Hatzenbuehler, M. L., Wang, K., Burton, C. L., Crawford, F. W., Phelan, J. C., \& Link, B. G. (2017). The Burden of Stigma on Health and Well-Being: A Taxonomy of Concealment, Course, Disruptiveness, Aesthetics, Origin, and Peril Across 93 Stigmas. Personality and Social Psychology Bulletin, 44(4), 451-474. doi:10.1177/0146167217741313

5. Montesinos-Magraner, L., Issa-Benítez, D., Pagès-Bolíbar, E., Meléndez-Plumed, M., González-Viejo, M. A., \& Castellano-Tejedor, C. (2016). Physical and Psychosocial Functions of Adults with Lower Limb Congenital Deficiencies and Amputations in Childhood. Rehabilitation Research and Practice, 2016(2), 1-7. doi:10.1155/2016/8109365

6. Udosen, A. M., Ngim, N., Etokidem, A., Ikpeme, A., Urom, S., \& Marwa, A. (2009). Attitude and perception of patients towards amputation as a form of surgical treatment in the University of Calabar teaching hospital, Nigeria. African health sciences, 9(4), 254-257.

7. Maroukis, B. L., Shauver, M. J., Nishizuka, T., Hirata, H., \& Chung, K. C. (2016). Cross-cultural variation in preference for replantation or revision amputation: Societal and surgeon views. Injury, 47(4), 818823. doi:10.1016/j.injury.2016.02.015

8. Nishizuka, T., Shauver, M. J., Zhong, L., Chung, K. C., \& Hirata, H. (2015). A Comparative Study of Attitudes Regarding Digit Replantation in the United States and Japan. The Journal of Hand Surgery, 4O(8), 1646-56-1656.e1-3. doi:10.1016/j.jhsa.2015.05.026

9. Shauver, M. J., Nishizuka, T., Hirata, H., \& Chung, K. C. (2016). Traumatic Finger Amputation Treatment Preference among Hand Surgeons in the United States and Japan. Plastic and Reconstructive Surgery, 137(4), 1193-1202. doi:10.1097/01.prs.0000481301.25977.80

10. Chung, K. C., Yoon, A. P., Malay, S., Shauver, M. J., Wang, L., Kaur, S., \& Group, F. T. F. (2019). PatientReported and Functional Outcomes After Revision Amputation and Replantation of Digit Amputations: The FRANCHISE Multicenter International Retrospective Cohort Study. JAMA Surgery, 154(7), 637-646. doi:10.1001/jamasurg.2019.0418

11. Pet M.A., Ko J.H. (2019) Indications for Replantation and Revascularization in the Hand. Hand Clin. 35(2), 119-130. 
12. Saxena, K., Sharma, A., Hussain, M. A. Z., Thombare, R. U., \& Bhasin, S. S. (2012). A Hollow Silicone Finger Prosthesis with Modified Metal-Mesh Conformer. The Journal of Indian Prosthodontic Society, 14(3), 301-304. doi:10.1007/s13191-012-0204-z

13. Cabibihan, J.-J. (2011). Patient-specific prosthetic fingers by remote collaboration-a case study. PLOS ONE, 6(5), e19508. doi:10.1371/journal.pone.0019508

14. Manrique, O. J., Ciudad, P., Doscher, M., Torto, Lo, F., Liebling, R., \& Galan, R. (2017). Osseointegrated Finger Prostheses Using a Tripod Titanium Mini-Plate. Archives of Plastic Surgery, 44(2), 150-156. doi:10.5999/aps.2017.44.2.150

15. Ma, H.-I., Saint-Hilaire, M., Thomas, C. A., \& Tickle-Degnen, L. (2016). Stigma as a key determinant of health-related quality of life in Parkinson's disease. Quality of Life Research, 25(12), 3037-3045. doi:10.1007/s11136-016-1329-z

16. Victorson, D., Cavazos, J. E., Holmes, G. L., Reder, A. T., Wojna, V., Nowinski, C., et al. (2014). Validity of the Neurology Quality-of-Life (Neuro-QoL) measurement system in adult epilepsy. Epilepsy \& Behavior, 31(C), 77-84. doi:10.1016/j.yebeh.2013.11.008

17. Carlozzi, N. E., Goodnight, S., Kratz, A. L., Stout, J. C., McCormack, M. K., Paulsen, J. S., et al. (2019). Validation of Neuro-QoL and PROMIS Mental Health Patient Reported Outcome Measures in Persons with Huntington Disease. Journal of Huntington's disease, 8(4), 467-482. doi:10.3233/JHD-190364

18. University of Wisconsin School of Medicine and Public Health. 2018 Area Deprivation Index Version 3.0 Downloaded from https://www.neighborhoodatlas.medicine.wisc.edu/ 11/1/2020. Retrieved January 22, 2021, from

19. Kind, A. J. H., \& Buckingham, W. R. (2018). Making Neighborhood-Disadvantage Metrics Accessible The Neighborhood Atlas. N Engl J Med, 378(26), 2456-2458. doi:10.1056/NEJMp1802313

20. Wright, M. A., Beleckas, C. M., \& Calfee, R. P. (2019). Mental and Physical Health Disparities in Patients With Carpal Tunnel Syndrome Living With High Levels of Social Deprivation. The Journal of Hand Surgery, 44(4), 335.e1-335.e9. doi:10.1016/j.jhsa.2018.05.019

21. Bernstein, D. N., Crijns, T. J., Mahmood, B., Ring, D., \& Hammert, W. C. (2019). Patient Characteristics, Treatment, and Presenting PROMIS Scores Associated with Number of Office Visits for Traumatic Hand and Wrist Conditions. Clinical orthopaedics and related research, 477(10), 2345-2355. doi:10.1097/CORR.0000000000000742

22. Okoroafor, U. C., Gerull, W., Wright, M., Guattery, J., Sandvall, B., \& Calfee, R. P. (2018). The Impact of Social Deprivation on Pediatric PROMIS Health Scores After Upper Extremity Fracture. The Journal of Hand Surgery, 43(10), 897-902. doi:10.1016/j.jhsa.2018.06.119

23. Wright, M. A., Adelani, M., Dy, C., O'Keefe, R., \& Calfee, R. P. (2019). What is the Impact of Social Deprivation on Physical and Mental Health in Orthopaedic Patients? Clinical orthopaedics and related research, 477(8), 1825-1835. doi:10.1097/CORR.0000000000000698

24. Soper, D. (n.d.). A-priori Sample Size Calculator for Multiple Regression. Retrieved from https://www.danielsoper.com/statcalc 
25. Cohen, J. (1988). Statistical Power Analysis for the Behavioral Sciences (Second Edition.). Hillsdale, $\mathrm{NJ}$ : Lawrence Earlbaum Associates.

26. Boulas, H. J. (1998). Amputations of the fingers and hand: indications for replantation. The Journal of the American Academy of Orthopaedic Surgeons, 6(2), 100-105.

27. Bookwala, J., 2017. (2017). AGE DIFFERENCES IN THE EFFECTS OF SELF-STIGMAS ON WELLBEING. Innivations in Aging, 1, 117. doi:10.1093/geroni/igx004.481

28. Carstensen, L. L., Isaacowitz, D. M., \& Charles, S. T. (1999). Taking time seriously. A theory of socioemotional selectivity. The American psychologist, 54(3), 165-181. doi:10.1037//0003066x.54.3.165

29. Naushad, N., Dunn, L. B., Muñoz, R. F., \& Leykin, Y. (2018). Depression increases subjective stigma of chronic pain. Journal of Affective Disorders, 229, 456-462. doi:10.1016/j.jad.2017.12.085

30. Fujihara, Y., Shauver, M. J., Lark, M. E., Zhong, L., \& Chung, K. C. (2017). The Effect of Workers' Compensation on Outcome Measurement Methods after Upper Extremity Surgery. Plastic and Reconstructive Surgery, 139(4), 923-933. doi:10.1097/PRS.0000000000003154

31. Murgatroyd, D. F., Casey, P. P., Cameron, I. D., \& Harris, I. A. (2015). The Effect of Financial Compensation on Health Outcomes following Musculoskeletal Injury: Systematic Review. PLoS ONE, 10(2), e0117597-33. doi:10.1371/journal.pone.0117597

32. Shifflett, G. D., Dy, C. J., \& Daluiski, A. (2012). Carpal tunnel surgery: patient preferences and predictors for satisfaction. Patient Preference and Adherence, 6, 685-689. doi:10.2147/PPA.S36088

33. Massey, D. S., \& Tourangeau, R. (2012). Where Do We Go from Here? Nonresponse and Social Measurement. The ANNALS of the American Academy of Political and Social Science, 645(1), 222236. doi:10.1177/0002716212464191

34. Berlin, N. L., Hamill, J. B., Qi, J., Kim, H. M., Pusic, A. L., \& Wilkins, E. G. (2018). Nonresponse bias in survey research: lessons from a prospective study of breast reconstruction. Journal of Surgical Research, 224, 112-120. doi:10.1016/j.jss.2017.11.058

35. Cochrane, S., Dale, A. M., Buckner-Petty, S., Sobel, A. D., Lippold, B., \& Calfee, R. P. (2020). Relevance of Diagnosed Depression and Antidepressants to PROMIS Depression Scores Among Hand Surgical Patients. The Journal of Hand Surgery, 29(2), 147. doi:10.1016/j.jhsa.2020.10.012

\section{Tables}


Table 1: Comparison of Entire Digital Amputee Cohort and Follow-up Study Cohort (Continuous Variables)

\begin{tabular}{|c|c|c|c|c|c|}
\hline \multirow[b]{2}{*}{ Explanatory Variable } & \multicolumn{2}{|c|}{$\begin{array}{l}\text { Entire Digital Amputee Cohort } \\
(\mathrm{n}=1109)\end{array}$} & \multicolumn{2}{|c|}{$\begin{array}{l}\text { Follow-up Study Cohort } \\
(\mathrm{n}=164)\end{array}$} & \multirow[t]{2}{*}{$\mathrm{p}$} \\
\hline & Mean & Standard Deviation & Mean & $\begin{array}{l}\text { Standard } \\
\text { Deviation }\end{array}$ & \\
\hline Age at Amputation (y) & 47.6 & 17.3 & 51.6 & 16.4 & 0.006 \\
\hline Area Deprivation Index & 61.7 & 23.6 & 50.9 & 24.1 & 0.000 \\
\hline Time Since Surgery (y) & 5.1 & 3.0 & 4.4 & 2.9 & 0.000 \\
\hline $\begin{array}{l}\text { Number of Amputated } \\
\text { Fingers }\end{array}$ & 1.5 & 1.1 & 1.4 & 1.1 & 0.281 \\
\hline
\end{tabular}


Table 2: Comparison of Entire Digital Amputee Cohort and Follow-up Study

Cohort

(Dichotomous and Interval Variables)

\begin{tabular}{|c|c|c|c|c|}
\hline & & $\begin{array}{l}\text { Entire Digital } \\
\text { Amputee Cohort } \\
(n=1109)\end{array}$ & $\begin{array}{l}\text { Follow-up Study } \\
\text { Cohort }(n=164)\end{array}$ & $\mathrm{p}$ \\
\hline \multirow[t]{2}{*}{ Gender } & Male & $884(80 \%)$ & $85(52 \%)$ & \multirow[t]{2}{*}{$<0.05$} \\
\hline & Female & $225(20 \%)$ & $79(48 \%)$ & \\
\hline \multirow[t]{5}{*}{ Ethnicity } & White & $747(67 \%)$ & $146(89 \%)$ & \multirow[t]{5}{*}{$<0.05$} \\
\hline & African American & $343(31 \%)$ & $15(9 \%)$ & \\
\hline & Hispanic & $5(<1 \%)$ & $0(0 \%)$ & \\
\hline & Asian & $9(1 \%)$ & $2(1 \%)$ & \\
\hline & Native American & $5(<1 \%)$ & $1(1 \%)$ & \\
\hline \multirow[t]{2}{*}{ Thumb Amputation } & Yes & $216(19 \%)$ & $30(18 \%)$ & \multirow[t]{2}{*}{0.720} \\
\hline & No & $893(81 \%)$ & $134(82 \%)$ & \\
\hline \multirow{7}{*}{$\begin{array}{l}\text { Most Proximal Level } \\
\text { (Non-Thumb) }\end{array}$} & Distal Phalanx & $317(29 \%)$ & $42(26 \%)$ & \multirow[t]{7}{*}{0.111} \\
\hline & $\begin{array}{l}\text { Distal } \\
\text { Interphalangeal Joint }\end{array}$ & $152(14 \%)$ & $18(11 \%)$ & \\
\hline & Middle Phalanx & $240(22 \%)$ & $16(10 \%)$ & \\
\hline & $\begin{array}{l}\text { Proximal } \\
\text { Interphalangeal Joint }\end{array}$ & $133(12 \%)$ & $12(7 \%)$ & \\
\hline & Proximal Phalanx & $217(20 \%$ & $17(10 \%)$ & \\
\hline & $\begin{array}{l}\text { Metacarpophalangeal } \\
\text { Joint }\end{array}$ & $171(15 \%)$ & $11(7 \%)$ & \\
\hline & Metacarpal & $198(18 \%)$ & $25(15 \%)$ & \\
\hline \multirow{5}{*}{$\begin{array}{l}\text { Most Proximal Level } \\
\text { (Thumb) }\end{array}$} & Distal Phalanx & $83(38 \%)$ & $11(37 \%)$ & \multirow[t]{5}{*}{0.574} \\
\hline & Interphalangeal Joint & $56(26 \%)$ & $8(27 \%)$ & \\
\hline & Proximal Phalanx & $44(20 \%)$ & $9(30 \%)$ & \\
\hline & $\begin{array}{l}\text { Metacarpophalangeal } \\
\text { Joint }\end{array}$ & $24(11 \%)$ & $2(7 \%)$ & \\
\hline & Metacarpal & $9(4 \%)$ & $0(0 \% 0$ & \\
\hline \multirow{3}{*}{$\begin{array}{l}\text { Dominant Side } \\
\text { Injury }\end{array}$} & Yes & $341(48 \%)$ & $80(50 \%)$ & \multirow[t]{3}{*}{0.652} \\
\hline & No & $369(52 \%)$ & $80(50 \%)$ & \\
\hline & Unknown & 388 & 4 & \\
\hline
\end{tabular}




\begin{tabular}{|lllll|}
\hline Mechanism & Trauma & $828(75 \%)$ & $128(78 \%)$ & 0.349 \\
\cline { 2 - 3 } & Other & $281(25 \%)$ & $36(22 \%)$ & \\
Workers & Yes & $290(28 \%)$ & $32(20 \%)$ & $<0.05$ \\
& No & $754(72 \%)$ & $132(80 \%)$ & \\
\cline { 2 - 3 } & Unknown & 65 & 0 & \\
\hline
\end{tabular}

\begin{tabular}{|llllll|}
\hline Table 3: Bivariate Relationships & Between Explanatory Variables and Neuro-QOL Stigma & \\
Explanatory Variable & $\begin{array}{l}\text { Unstandardized } \\
\text { Beta }\end{array}$ & $\begin{array}{l}\text { Standard } \\
\text { Error }\end{array}$ & $\begin{array}{l}\text { Standardized } \\
\text { Beta }\end{array}$ & $\begin{array}{l}\text { R- } \\
\text { Squared }\end{array}$ & $p$ \\
\hline Time Since Amputation (y) & -0.04 & 0.21 & -0.14 & 0.000 & 0.855 \\
\hline Age at Amputation (y) & -0.13 & 0.035 & -0.281 & 0.079 & $<0.05$ \\
\hline Male Gender & -1.384 & 1.181 & -0.092 & 0.008 & 0.243 \\
\hline Area Deprivation Index & 0.058 & 0.024 & 0.184 & 0.034 & $<0.05$ \\
\hline $\begin{array}{l}\text { Education Level (Associate's } \\
\text { or Higher) }\end{array}$ & -2.706 & 1.19 & -0.179 & 0.024 & $<0.05$ \\
\hline Depression at Time of Injury & 4.2 & 2.03 & 0.161 & 0.030 & $<0.05$ \\
\hline Number of Amputated Digits & 0.818 & 0.53 & 0.12 & 0.140 & 0.125 \\
\hline Thumb Involvement & 1.598 & 1.528 & 0.082 & 0.007 & 0.297 \\
\hline Proximal Amputation Level & 0.39 & 1.19 & 0.026 & 0.328 & 0.743 \\
\hline Dominant Side Injury & 1.731 & 1.191 & 0.115 & 0.130 & 0.15 \\
\hline Traumatic Mechanism & 0.805 & 1.431 & 0.044 & 0.002 & 0.574 \\
\hline Worker's Compensation & 4.7 & 1.45 & 0.25 & 0.060 & $<0.05$ \\
\hline
\end{tabular}




\begin{tabular}{|l|lllll|}
\hline \multicolumn{4}{|l|}{$\begin{array}{l}\text { Table 4: Final Model for Neuro-QOL Stigma in Digital Amputees after Stepwise Multivariable } \\
\text { Regression (Entered variables with bivariate } \mathbf{p}<0.2)\end{array}$} & \\
\hline $\begin{array}{l}\text { R- } \\
\text { Squared }\end{array}$ & Explanatory Variable & $\begin{array}{l}\text { Unstandardized } \\
\text { Beta }\end{array}$ & $\begin{array}{l}\text { Standard } \\
\text { Error }\end{array}$ & $\begin{array}{l}\text { Standardized } \\
\text { Beta }\end{array}$ & $\mathrm{p}$ \\
\hline 0.15 & 0.12 & 0.03 & -0.25 & $<0.05$ \\
\hline & Age at Amputation & 4.00 & 1.42 & 0.21 & $<0.05$ \\
\cline { 2 - 6 } & $\begin{array}{l}\text { Workers Compensation } \\
\begin{array}{l}\text { Depression at Time of } \\
\text { Amputation }\end{array}\end{array}$ & 4.22 & 1.93 & 0.16 & $<0.05$ \\
\hline
\end{tabular}

\begin{tabular}{|lcc|}
\hline \multicolumn{4}{|l|}{ Table 5: Correlation Between Neuro-QOL Stigma and Other Functional and Psychosocial Outcomes } \\
\hline Secondary PRO Measures & Pearson's r & $p$ \\
\hline PROMIS Upper Extremity Function & -0.56 & $<0.05$ \\
\hline PROMIS Depression & 0.69 & $<0.05$ \\
\hline PROMIS Anxiety & 0.61 & $<0.05$ \\
\hline PROMIS Anger & 0.56 & $<0.05$ \\
\hline PROMIS Ability to Participate in Social Roles and Activities & -0.64 & $<0.05$ \\
\hline PROMIS Pain Interference & 0.54 & $<0.05$ \\
\hline
\end{tabular}

\section{Figures}




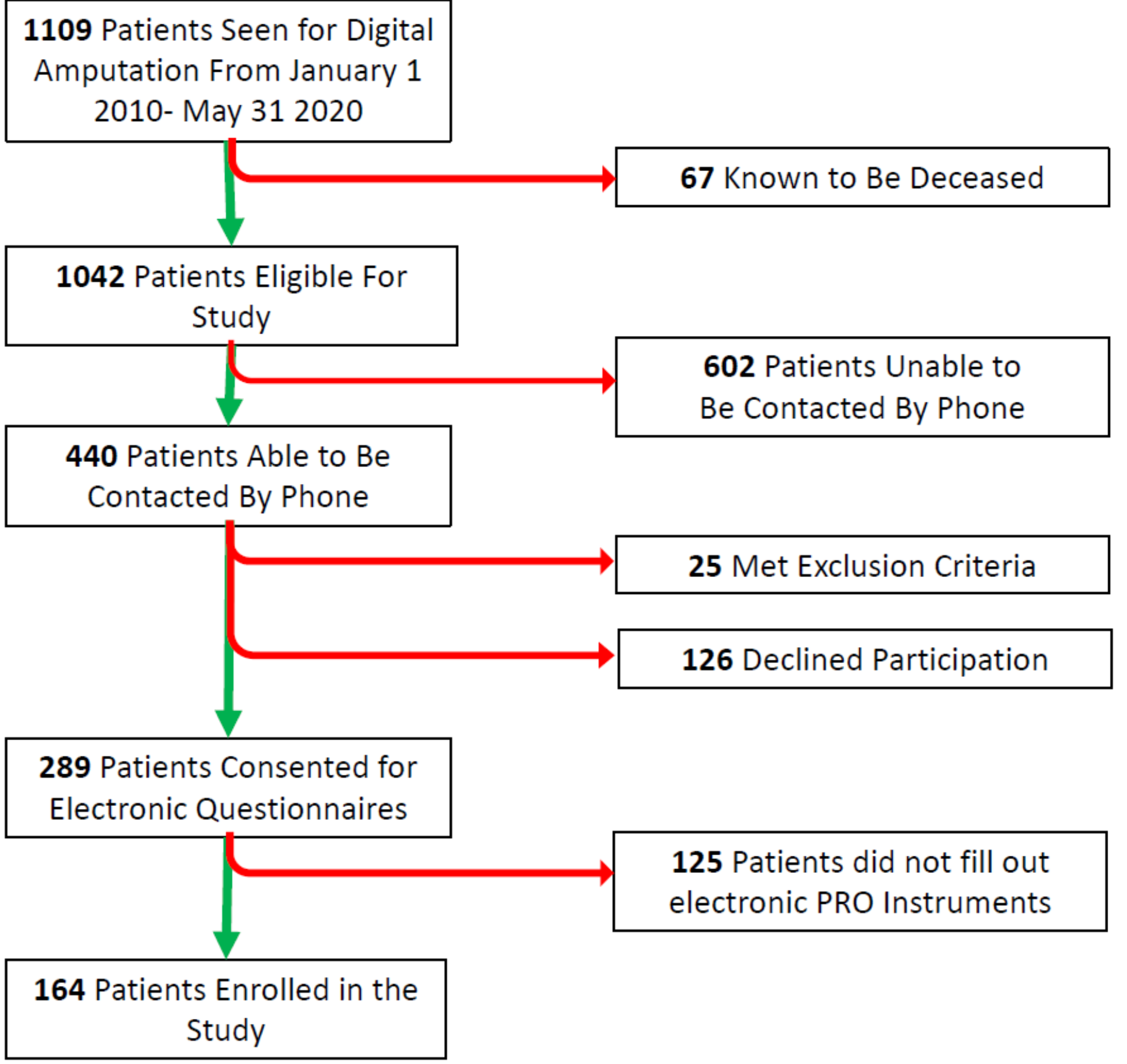

Figure 1

Flow diagram detailing eligible patient inclusion and exclusion from the follow-up group. 
Neuro-QOL Stigma Histogram

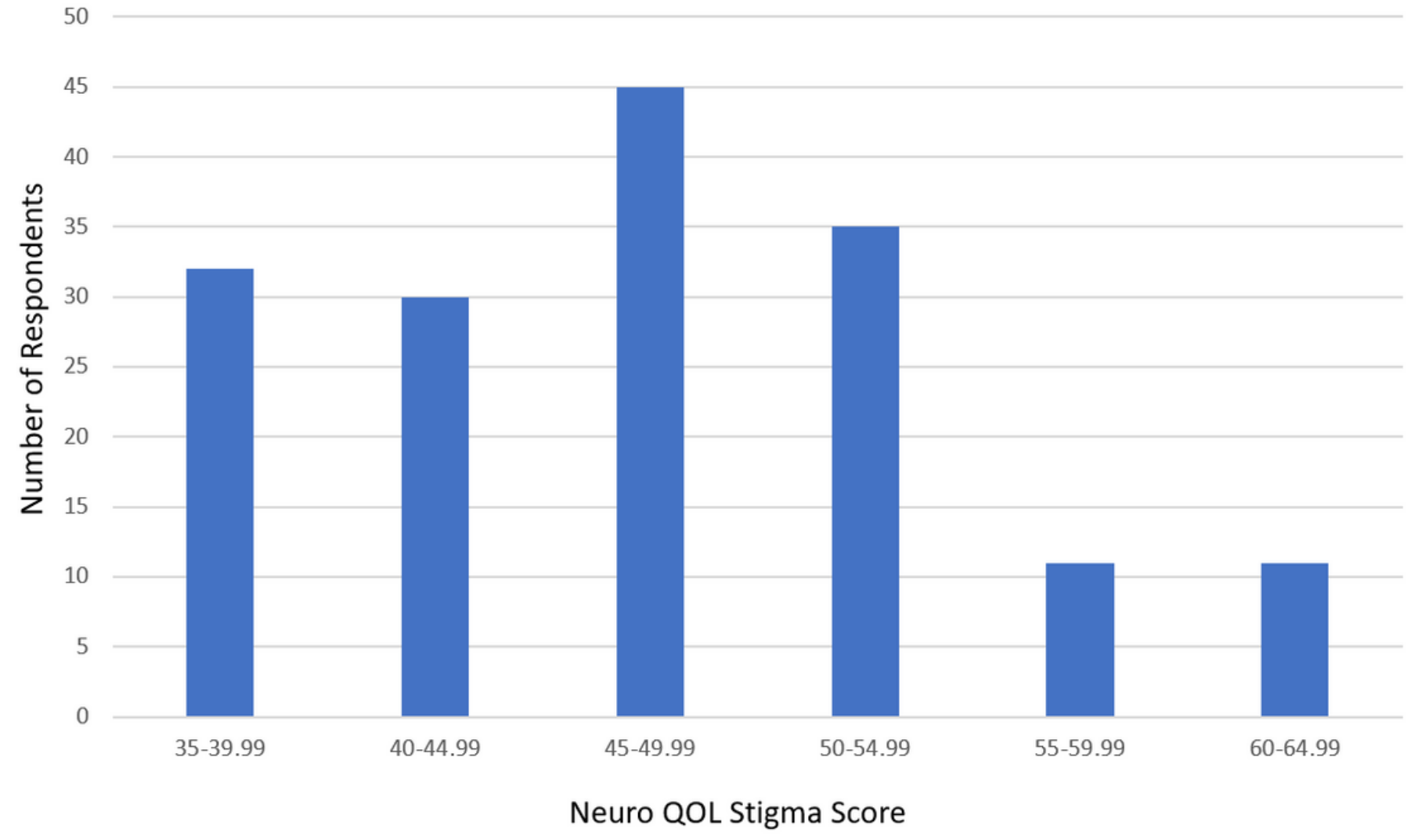

Figure 2

Histogram demonstrating the distribution of Neuro-QOL scores in the respondent digital amputee population.

\section{Supplementary Files}

This is a list of supplementary files associated with this preprint. Click to download.

- Appendix1STIGMAltemBank.pdf

- SPSSDataAllRespondents.sav 